\title{
Surveillance, Epidemiology, and End Results Program
}

National Cancer Institute

\section{Source}

National Cancer Institute. Surveillance, Epidemiology, and End Results Program. NCI

Thesaurus. Code C15432.

A program of the National Cancer Institute that provides information on cancer statistics

in an effort to reduce the cancer burden among the U.S. population. 